\title{
Acute on chronic osteomyelitis due to coliforms in a Sri Lankan child with homozygous sickle cell disease
}

\author{
T J Hoole ${ }^{1}$, V Arunath ${ }^{1}$, M H A D de Silva ${ }^{2}$, O G W Muthukumarana ${ }^{1}$ I M Kumarasiri ${ }^{1}$, G B A M \\ Rathnasiri $^{1}$, Gayana Mahendra ${ }^{3}$, Anuja Premawardhena ${ }^{1,3}$, *Sachith Mettananda ${ }^{1,3}$ \\ Sri Lanka Journal of Child Health, 2021; 50(3): 558-560 \\ DOI: http://doi.org/10.4038/sljch.v50i3.9749 \\ (Key words: Acute on chronic osteomyelitis, coliforms, homozygous sickle cell disease, child, Sri Lanka)
}

\begin{abstract}
Introduction
Homozygous sickle cell disease (Hb SS) or sickle cell anaemia is extremely rare in Sri Lanka ${ }^{1}$. Although osteomyelitis is a frequent complication of sickle cell disease, chronic osteomyelitis due to coliform bacteria is uncommon. This picture story describes a Sri Lankan girl with homozygous sickle cell disease who developed acute on chronic osteomyelitis due to coliforms.
\end{abstract}

\section{Case report}

A 10-year old Sri Lankan Sinhalese girl, who was diagnosed to have homozygous sickle cell disease, was transferred to our unit due to prolonged fever and generalised body pain of one-month duration. She was born to consanguineous parents with sickle cell trait. In the past, this child has had multiple episodes of dactylitis and acute vasoocclusive pain and had been receiving infrequent blood transfusions. She also had avascular necrosis of the left femoral head. Before admission to our unit, the child had received multiple courses of antibiotics including intravenous flucloxacillin, clindamycin, amikacin and teicoplanin for which she did not show a response. On admission, she was on intravenous meropenem, oral azithromycin, hydroxyurea and folic acid. On examination, the child appeared ill and pale. Swelling and tenderness were observed in the upper half of both legs over tibiae with restricted movements in both knee joints. Abdominal examination revealed a 2 $\mathrm{cm}$ splenomegaly without hepatomegaly.

${ }^{1}$ Colombo North Teaching Hospital, Ragama, Sri Lanka, ${ }^{2}$ Faculty of Medicine, University of Ruhuna, Galle, Sri Lanka, ${ }^{3}$ Faculty of Medicine, University of Kelaniya, Ragama, Sri Lanka

*Correspondence: sachith.mettananda@kln.ac.lk

iD https://orcid.org/0000-0002-0760-0418

(Received on 15 May 2020: Accepted after revision on 19 June 2020)

The authors declare that there are no conflicts of interest

Personal funding was used for the project.

Open Access Article published under the Creative

Commons Attribution CC-BY (cc) (†) License
Cardiovascular, respiratory and nervous system examinations were normal. Based on examination findings, osteomyelitis of bilateral tibiae or ischaemic pain due to vaso-occlusive disease associated with sepsis, was suspected.

Complete blood count showed a haemoglobin $(\mathrm{Hb})$ level of $8.3 \mathrm{~g} / \mathrm{dl}$, a white cell count of $12,500 / \mu \mathrm{l}$ (neutrophils 70\%, lymphocytes 24\%), and a platelet count of $385,000 / \mu$ l. C-reactive protein was $193 \mathrm{mg} / \mathrm{l}$ and erythrocyte sedimentation rate was $141 \mathrm{~mm} / \mathrm{hr}$. Hb capillary electrophoresis showed $44 \% \mathrm{HbS}, 39 \% \mathrm{HbA}, 2 \% \mathrm{HbA}_{2}$ and $14 \% \mathrm{HbF}$ (Figure 1). Her renal function tests, serum electrolytes and hepatic transaminases were normal and blood and urine cultures were sterile. Radiographs of both lower limbs showed thickened periosteum, endosteal scalloping and regional osteopenia of bilateral tibiae suggestive of osteomyelitis (Figure 2).

Intravenous vancomycin was commenced while intravenous meropenem was continued. A central venous line was inserted. Pain was managed with regular paracetamol and ibuprofen along with morphine given on as required basis. Repeated transfusions with leuco-depleted packed red blood cells were done to maintain $\mathrm{HbS}$ below $30 \%$. Despite treatment, the child continued to have severe pain and intermittent fever. Magnetic resonance imaging (MRI) of both lower limbs performed at this stage showed well demarcated serpiginous areas of high signal intensity in T2weighted short-tau inversion recovery (T2w-STIR) images involving the left tibial diaphysis and upper half of the right tibial diaphysis (Figure 3).

There was associated solid periosteal reaction and surrounding soft tissue oedema on both sides. Left femoral diaphysis showed similar lesions. Bilateral lower limb osteotomy and drainage was performed on the ninth day after admission. Pus was drained from bilateral tibia and left lower femur. Pus culture was positive for lactose-fermenting coliforms and the bone histology confirmed acute on chronic osteomyelitis with mixed inflammatory cell infiltration and fibrosis of the marrow space (Figure 4). 

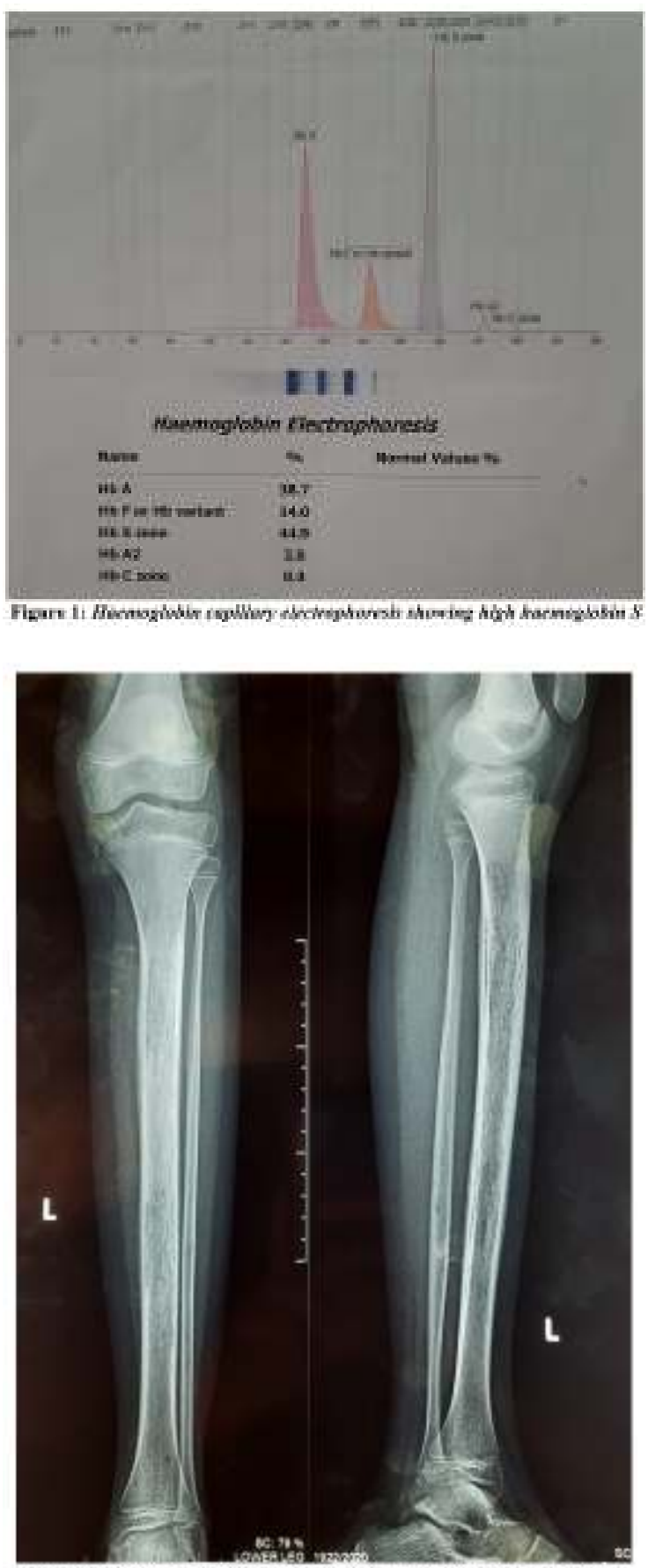

Figure 2: Plain X-ray of the left leg showing thickened periosteum, endosteal scalloping and regional osteopenia of tibia

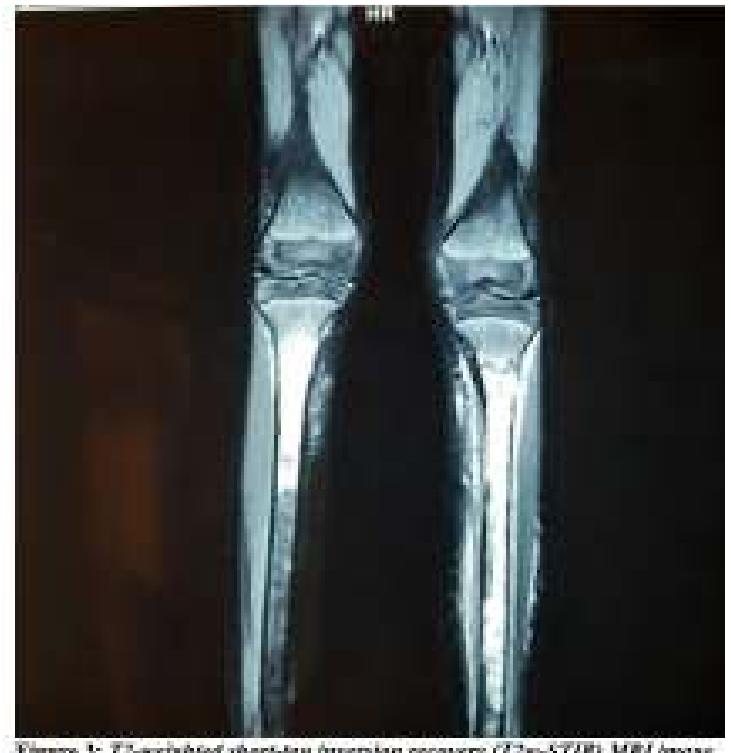

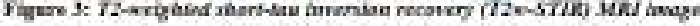

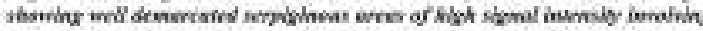

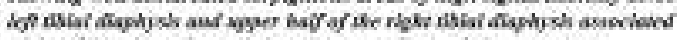

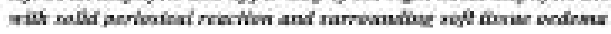

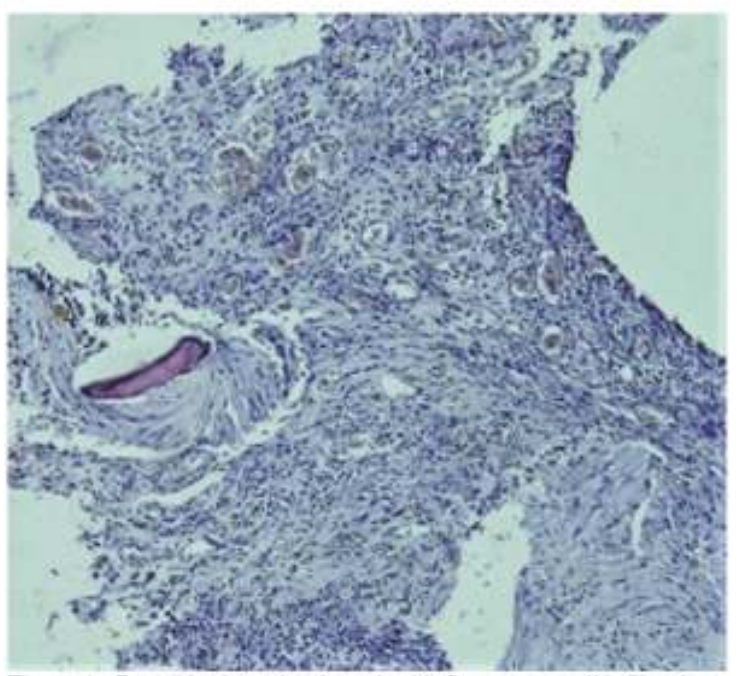

Figure 4: Bone histology showing mixed inflammatory cell infiltration and fibrosis of the marrow space. $A$ fragment of dead bone is seen in the left side of the photomicrograph ( $H$ and $E$ stain; magnification $x$ 100)

Based on the antibiotic sensitivity pattern, intravenous meropenem was continued for a total of six weeks and intravenous ciprofloxacin was given for two weeks. Vancomycin was discontinued after three weeks. The child showed significant clinical improvement with settling of fever and normalisation of inflammatory markers. She was discharged home with oral ciprofloxacin for another two weeks and was advised to continue oral hydroxyurea. During a review three weeks after being discharged, she remained well, free of pain, afebrile and had a full range of movement in both hip and knee joints. 


\section{Discussion}

Sickle cell disease is relatively uncommon in Sri Lanka with approximately sixty patients reported in the country so far. Of them, most are compound heterozygous for $\mathrm{HbS}$ and beta thalassaemia, known as HbS beta thalassaemia. Only six patients with homozygous sickle cell disease have been reported in the country ${ }^{2}$. Osteomyelitis is an important differential diagnosis for long bone pain in children with sickle cell disease ${ }^{3}$. Radiological features are non-specific and include osteopenia, sclerosis and periosteal inflammation. These changes occur in infection as well as in necrosis which is another complication of sickle cell disease. MRI is the most useful imaging modality to diagnose osteomyelitis and provides additional information regarding soft tissue involvement, abscess formation and venous thrombosis ${ }^{4}$.

Due to functional asplenia, patients with sickle cell disease are prone to infections with encapsulated organisms that include Streptococcus pneumoniae, Haemophilus influenzae $\mathrm{b}$ and Neisseria meningitidis ${ }^{5}$. Staphylococcus aureus and Salmonella are the common organisms to cause osteomyelitis in these patients ${ }^{6}$. Osteomyelitis in our patient was caused by coliforms which is a relatively uncommon aetiology in children with sickle cell disease ${ }^{7}$. In conclusion, this picture story describes the approach to long bone pain in a child with sickle cell disease and highlights the importance of performing neuroimaging with MRI in situations of diagnostic uncertainties. Furthermore, it highlights the importance of considering a wide spectrum of aetiological agents when deciding on empirical antibiotic treatment for suspected osteomyelitis in children with sickle cell disease.

\section{Acknowledgements}

We acknowledge the support received from the staff of orthopaedic, anaesthesiology, radiology and microbiology units of the Colombo North Teaching Hospital for the management of this child.

\section{References}

1. Premawardhana AP, Mudiyanse R, De Silva ST, Jiffry N, Nelumdeniya U, de Silva U, et al. A nationwide survey of hospital-based thalassaemia patients and standards of care and a preliminary assessment of the national prevention program in Sri Lanka. PloS one 2019; 14(8): 0220852 .

https://doi.org/10.1371/journal.pone.0220 852

PMid: 31419232 PMCid: PMC6697367
2. Darshana T, Malaviarachchi S, Nawaratna USB, Costa YJ, Nizri AHM, Silva DPSI, et al, editors. Genetic origins and clinical variability of sickle cell disease in Sri Lanka. $131^{\text {st }}$ Anniversary International Medical Congress of the Sri Lanka Medical Association 2018; Colombo.

3. Morrissey BJ, Bycroft TP, Almossawi O, Wilkey OB, Daniels JG. Incidence and predictors of bacterial infection in febrile children with sickle cell disease. Hemoglobin 2015; 39(5):316-9.

4. Acute and chronic bone complications of sickle cell disease [Internet]. 2019 [cited20/11/2019]. Available from: https:/www.uptodate.com/contents/acuteand-chronic-bone-complications-of-sicklecell-disease.

5. Thanni LO. Bacterial osteomyelitis in major sickling haemoglobinopathies: geographic difference in pathogen prevalence. African Health Sciences 2006; 6(4):236-9.

6. Martí-Carvajal AJ, Agreda-Pérez LH. Antibiotics for treating osteomyelitis in people with sickle cell disease. The Cochrane Database of Systematic Reviews 2016; 11(11):Cd007175.

https://doi.org/10.1002/14651858.CD0071 75.pub4

PMCid: PMC6734123

7. Alima Yanda AN, Nansseu JRN, Mbassi Awa HD, Tatah SA, Seungue J, Eposse C, et al. Burden and spectrum of bacterial infections among sickle cell disease children living in Cameroon. $B M C$ Infectious Diseases 2017; 17(1):211. https://doi.org/10.1186/s12879-017-23179

PMid: 28298206 PMCid: PMC5353947 